\title{
Tribological Polymerization of 2-Dibutylamino- 1,3,5-Triazine-4,6-dithiol on Iron Wire during Drawing
}

\author{
Kunio Mori, * Hidetoshi Hirahara, * Yoshiyuki Oishi, \\ and Masanori KataYAMA** \\ * Department Applied Chemistry \& Molecule Science Faculty of Engineering, \\ Iwate University, Ueda, Morioka 020, Japan \\ ** R\&D section, Tokyo Seiko Steel Cord Co., Ltd., \\ Murasakino, Kitakami 024, Japan
}

(Received May 10, 1995)

\begin{abstract}
KEY WORDS Tribological Polymerization / Triazine Dithiol / Wire Drawing / Nascent Surface / Disulfide Polymer / Monosulfide Network Poymer /
\end{abstract}

Tribological surface treatment makes possible the unification of processing and surface treatment of metal and lessens the requirement for metal processing. Tribological reactions of organic compounds with solid substances have been studied. Taubmann ${ }^{1}$ and Momose ${ }^{2}$ report mechanochemical polymerization to occur by milling inorganic substances in monomers. Mori and Tamai $^{3}$ found vibromilled aluminum and silica powders to be effective as anionic initiators for the polymerization of vinyl acetate, styrene, methylmethacrylate, and acrylonitrile but not iron powders. They ${ }^{4}$ describe reactions of butylbromide with aluminum under vibromilling to give a polymerized material on aluminum powders. Such treatment is not always effective for improving general metal surfaces such as plates, wires and blocks with organic compounds since milling for long periods is required. The present authors directed attention to these studies to determine how exoelectrons are generated during and after substance processing.

In this study, 2-dibutylamino-1,3,5-triazine4,6-dithiol was found to polymerize itself during wire drawing to give a linear polymer on wire surfaces and to react with double-bond compounds during wire drawing to give a net work polymer on a surface.

\section{EXPERIMENTAL}

2-Dibutylamino-1,3,5-triazine-4,6-dithiol (DB, $\mathrm{mp} 140^{\circ} \mathrm{C}$ ) and trially iso-cyanurate (TAIC mp $24^{\circ} \mathrm{C}$ ) were obtained commercially. Steel wire (JIS-AWRH82: Fe, over $98.51 \%$, C, $0.83 \%, \mathrm{Si}, 0.25 \%$; Mn, $0.45 \%$; P, below $0.03 \%$; S, below $0.03 \%$ ) was also purchased. Each wire sample was immersed for $5 \mathrm{~min}$ at $20^{\circ} \mathrm{C}$ in $1 \%-\mathrm{HCl}$ aqueous solution and then $1 \%-\mathrm{NaOH}$ aqueous solution and washed with methanol and dried in dry air ( oxide film: about $10 \mathrm{~nm}$ ).

Steel wire samples $(1.43 \phi \mathrm{m})$ pretreated above were drawn from a starting diameter of $1.43 \mathrm{~mm}$ to a final diameter of $1.30 \mathrm{~mm}$ in 2 passes by a dry drawing machine with a die box containing DB or a mixture of $\mathrm{DB}$ and TAIC. Drawing tests were conducted using DB and a mixture of DB and TAIC (1/1 molar ratio) as lubricants in normal production lines. The dies for drawing steel wire were standard 
tungsten carbide dies.

Molecular weight and distribution were determined by gel permeation chromatography (GPC, Shimadzu GPC SWRH82A) using tetrahydrofuran (THF) sample solutions prepared by immersing drawn wires in THF for $30 \mathrm{~min}$ at $30^{\circ} \mathrm{C}$ and Showadex GPC columns (KF-802, 804, and 805; exclusion limited molecular weight, $\left.5 \times 10^{5}\right)$. A UV detector $(254 \mathrm{~nm})$ was used to detect organic compounds.

FT-IR spectra were measured using a Nippon Denshi FT-IR, IR-5500 (Nippon Denshi Co., Ltd.) according to the ATR method. ESCA spectra were obtained at a base pressure of $10^{-9}$ Torr on an X-ray photoelectron spectrometer (ESCA Lab-5, VG Scientific Co., Ltd.). A take-off angle of $35^{\circ}$ was used with $\mathrm{Mg}-\mathrm{K}_{\alpha} \mathrm{X}$-ray as the excitation source $(23500 \mathrm{eV})$. AES spectra were obtained at a base pressure of $10^{-7}$ Torr on an Auger electron spectrometer (AES: JEOL; JAMP10S). A take-off angle of $0^{\circ}$ was used with Mg- $\mathrm{K}_{\alpha} \mathrm{X}$-ray as the excitation source $(23500$ $\mathrm{eV})$. The etching rate by $\mathrm{Ar}^{+}$was $18 \mathrm{~nm} \mathrm{~min}^{-1}$.

\section{RESULTS AND DISCUSSION}

\section{Polymerization during Steel Wire Drawing}

Metals assume activated surfaces during processing such as drawing, cutting, drilling, and rolling. This activity decreases rapidly in air. Active surfaces may cause organic compounds to change. ${ }^{5-7}$ Through the die box, steel wires were drawn in the presence of DB and a mixture of DB and TAIC as lubricants at various drawing rates. Figure 1 shows the GPC patterns of THF solutions obtained by extraction of the wires drawn using only DB and a mixture of DB and TAIC as lubricants; no stearic-type lubricants were used. After drawn, the wires were kept for 12 hours at room temperature. Six cut wires $(10 \mathrm{~cm}$ in length) were immersed in THF $(20 \mathrm{ml})$ and organic products adhering to the wire surfaces were dissolved in THF. Using the THF solutions, GPC pattern was used to determine mo- lecular weights and distributions of the extracted organic compounds. By drawing as shown in Figure 1 (No. 1), DB monomer was polymerized on wire surfaces. Molecular and polymer weights increased with the drawing rate. At low drawing rate $\left(b, 10 \mathrm{~m} \mathrm{~min}^{-1}\right)$, these parameters were small but increased at a high drawing rate $\left(\mathrm{d}, 50 \mathrm{~m} \mathrm{~min}^{-1}\right)$ markedly. The polymer films contained DB and DB oligomers as well as the DB polymer. The coefficients of the UV adsorption of DB $(\varepsilon$, $\left.1.7 \times 10^{4} \mathrm{~mol} \mathrm{l}^{-1}\right)$ and DB disulfide polymer $(\varepsilon$, $1.9 \times 10^{4} \mathrm{moll}^{-1}$ ) at $254 \mathrm{~nm}^{8}$ showed the amount of unreacted DB to be considerably smaller than that of a polymer. The treated wire surfaces after immersion in methanol had only DB polymer films with molecular weights of about 3000 to 200000 . Increased drawing rates caused wire surface temperature to increase $^{9-13}$ as well as molecular weight and polymer weight to increase. Tribological poly-

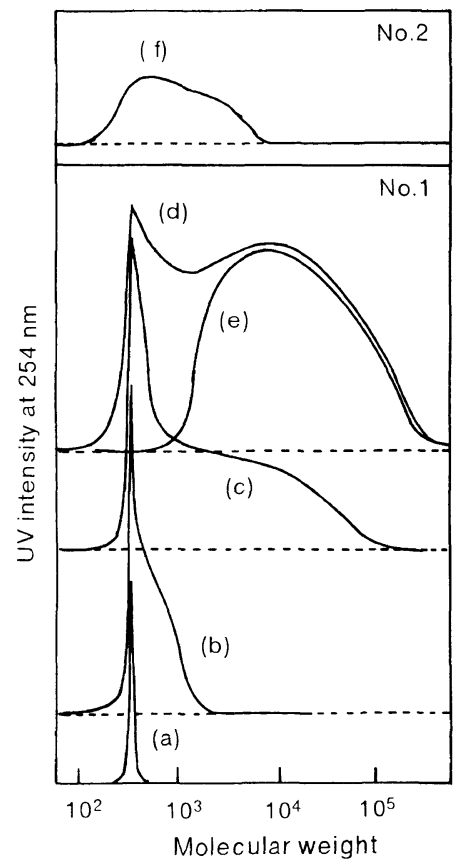

Figure 1. GPC patterns of polymers formed on steel wire during drawing. (a) DB, no drawing; (b) DB, drawing rate $10 \mathrm{~m} \mathrm{~min}^{-1}$; (c) $\mathrm{DB}$, drawing rate $30 \mathrm{~m} \mathrm{~min}^{-1}$; (d) $\mathrm{DB}$, drawing rate $50 \mathrm{~m} \mathrm{~min}^{-1}$; (e) washed sample; (d) with methanol; (f) DB+TAIC, drawing rate $50 \mathrm{~m} \mathrm{~min}^{-1}$. 
merization appears to run to completion instantly. No differences in molecular weight due to standing time, $10 \mathrm{~min}$ and 24 hours, after drawing could be detected. A mixture of DB and TAIC was also used as a lubricant in the drawing of iron wires at a drawing rate of $50 \mathrm{~m}$ $\min ^{-1}$, the maximum rate in the drawing test. GPC patterns indicated the formed film to contain DB, TAIC, and their polymers as shown in Figure 1 (No. 2). The intensity of UV adsorption of the polymer in the mixture was low, compared with that in DB. Thus possibly, a polymer insoluble in THF may form on wire during drawing. Both DB and TAIC may react with each other to form three dimensional organic film on wires during drawing.

Polymer film thickness on treated wires was determined based on AES as shown in Figure 2. Measurements were conducted after immersing the samples in methanol and removing monomers. Oxide film thickness on original wire surfaces was about $10 \mathrm{~nm}$. When DB was used as lubricant at a drawing rate of $50 \mathrm{~m} \mathrm{~min}^{-1}$, thickness of the polymer film on the wires was about $180 \mathrm{~nm}$. THF insoluble film prepared using the mixture of DB and TAIC was about $225 \mathrm{~nm}$ in organic film thickness. Thickness was determined as the point of intersection on the curves of carbon and iron atom content. Polymers are formed during drawing and thus organic film on iron wires should generally be thick. Organic film thickness may improve the surface properties of wire.

\section{Chemical Structures of Polymer Films}

To elucidate the chemical structures of polymer films, FT-IR spectrum measurements were made for treated wires. Steel wire surfaces treated by DB during drawing showed essentially the same FT-IR spectral patterns as

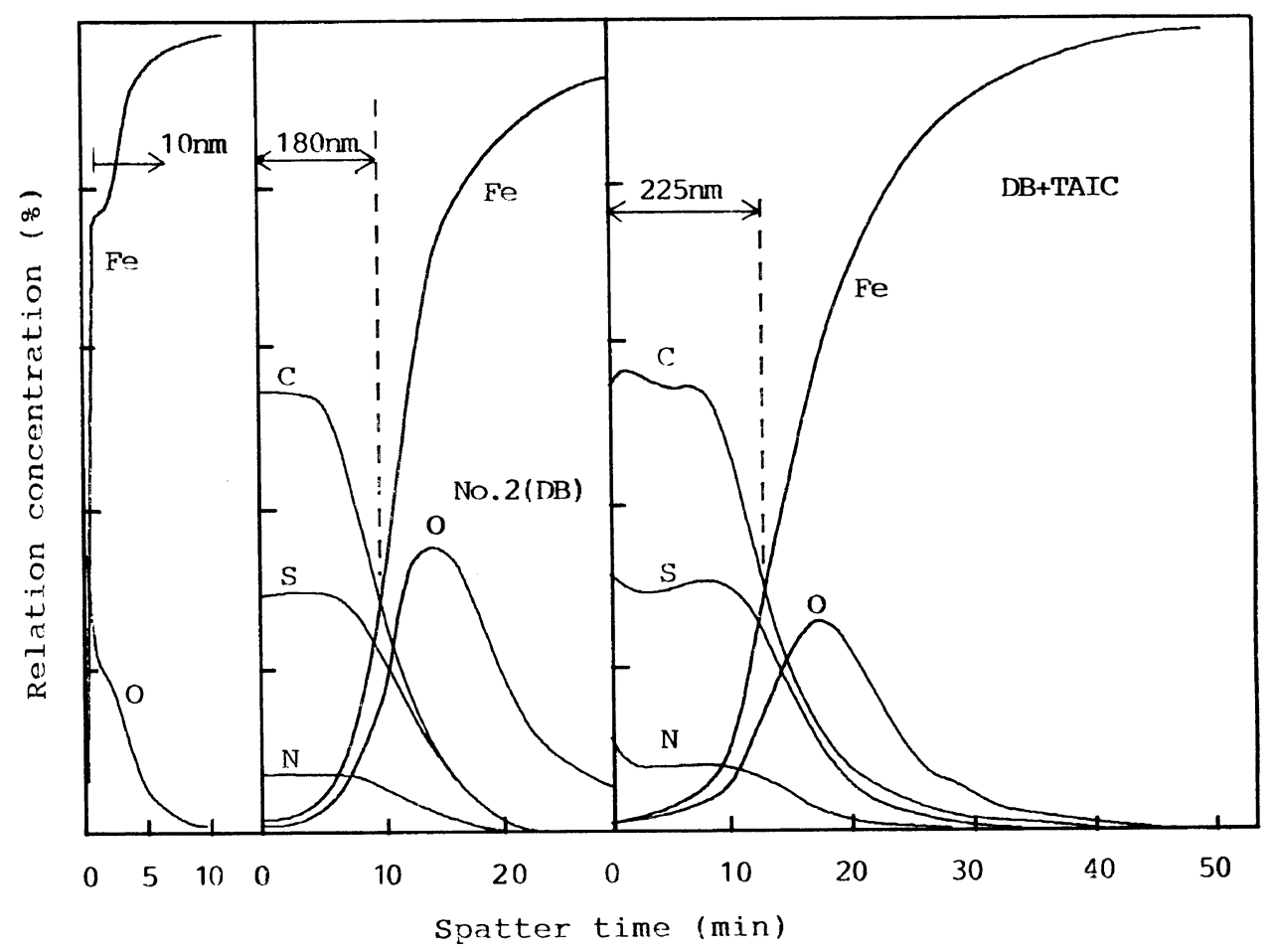

Figure 2. Changes in component atoms of wire surfaces after drawing at $50 \mathrm{~m} \mathrm{~min}^{-1}$ in the presence of $\mathrm{DB}$ and a mixture of DB and TIAC. 


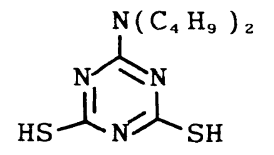

DB

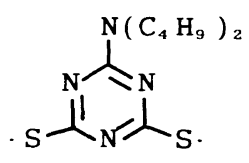
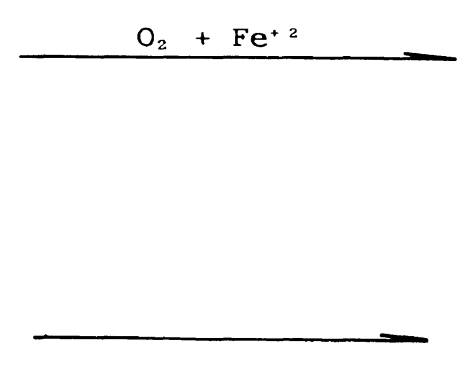

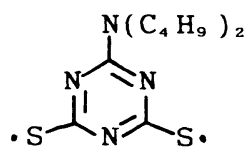

Dithiyl radical

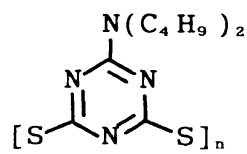<smiles>C=CCn1c(=O)n(CC=C)c(=O)n(CC=C)c1=O</smiles>

TAIC<smiles>CCCCn1c(=O)n(CCC)c(=O)n(CCCCSc2nc([Sb])nc(N(CC)CCC)n2)c1=O</smiles>

Three dimensional polymer

Figure 3. Polymerization of DB and a mixture of DB and TAIC on steel wires during drawing.

authentic DB disulfide polymer ${ }^{14}$ prepared separately although the spectra differed from that of DB. The sample after immersion in THF showed no absorption in the FT-IR spectrum. DB treated wires thus shed all organic films by THF immersion. Before immersion, they were covered with a linear polymer. Steel wires treated with a mixture of DB and TAIC during drawing showed clear IR spectrum patterns even though the samples had been extracted with THF. An absorption peak due to $\mathrm{CO}$ stretching vibration at $1715 \mathrm{~cm}^{-1}$ (TAIC), $\mathrm{C}=\mathrm{C}$ bond at $1635 \mathrm{~cm}^{-1}$ (TAIC), $\mathrm{C}=\mathrm{N}$ bond at $1559 \mathrm{~cm}^{-1}$, and $1525 \mathrm{~cm}^{-1}$ (DB) was seen. Decrease in absorption due to $\mathrm{C}=\mathrm{C}$ bonds in TAIC and
-NHCS-group $\left(1601 \mathrm{~cm}^{-1}\right)$ in DB suggests the formation of monosulfide groups. ${ }^{8}$ Only TAIC treated wire showed no adsorption peaks in FT-IR spectra following THF immersion. TAIC and DB in combination gave an insoluble polymer film by reaction of $\mathrm{C}=\mathrm{C}$ bonds in TAIC with the -NHCS-group in DB. To further elucidate the chemical structure of a polymer on treated wire, ESCA spectra were measured for samples extracted with methanol. Table I show the results of electron spectra in ESCA wide scan of wire surface of the drawing at $50 \mathrm{~m} \mathrm{~min}^{-1}$ in the presence of DB and a mixture of lubricants and assignments of functional groups based on $\mathrm{C}_{1 \mathrm{~S}}, \mathrm{~N}_{1 \mathrm{~S}}$, and $\mathrm{S}_{2 \mathrm{P}}$. DB and a mixture of DB and TAIC-treated 
Table I. Assignments of bonding energy for $\mathrm{C}_{1 \mathrm{~S}}, \mathrm{~N}_{1 \mathrm{~S}}$, and $\mathrm{S}_{2 \mathrm{P}}$ on a narrow scan in ESCA spectra

\begin{tabular}{|c|c|c|c|c|}
\hline \multirow{2}{*}{ Lubricant } & \multirow{2}{*}{$\begin{array}{l}\text { Electron } \\
\text { spectrum }\end{array}$} & Bonding energy & \multirow{2}{*}{ Bond groups } & \multirow{2}{*}{ Component } \\
\hline & & $\mathrm{eV}$ & & \\
\hline \multirow[t]{3}{*}{ DB } & $\mathrm{C}_{1 \mathrm{~s}}$ & $\begin{array}{l}286.61 \\
286.00 \\
287.57\end{array}$ & $\begin{array}{c}-\mathrm{CH}_{2}-,-\mathrm{CH}_{3} \\
>\mathrm{C}=\mathrm{N}- \\
>\mathrm{C}-\mathrm{N}<\end{array}$ & $\begin{array}{l}63 \\
22 \\
15\end{array}$ \\
\hline & $\mathrm{N}_{1 \mathrm{~S}}$ & $\begin{array}{l}398.66 \\
399.98\end{array}$ & $\begin{array}{l}-\mathrm{N}=\mathrm{C}< \\
>\mathrm{C}-\mathrm{N}<\end{array}$ & $\begin{array}{l}58 \\
42\end{array}$ \\
\hline & $\mathrm{S}_{2 \mathrm{P}}$ & $\begin{array}{l}162.0,163.1 \\
163.4,165.2 \\
168.1,169.5\end{array}$ & $\begin{array}{c}-\mathrm{SS}- \\
>\mathrm{C}-\mathrm{S}- \\
>\mathrm{C}-\mathrm{SO}_{n}^{-}\end{array}$ & $\begin{array}{r}46 \\
47 \\
7\end{array}$ \\
\hline \multirow[t]{3}{*}{ DB/TAIC } & $\mathrm{C}_{1 \mathrm{~s}}$ & $\begin{array}{l}286.61 \\
287.02\end{array}$ & $\begin{array}{c}-\mathrm{CH}_{2-},-\mathrm{CH}_{3} \\
-\mathrm{CH}=,=\mathrm{CH}_{2} \\
>\mathrm{C}-\mathrm{N}<,>\mathrm{C}=\mathrm{N}- \\
>\mathrm{C}=\mathrm{O}\end{array}$ & $\begin{array}{l}66 \\
34\end{array}$ \\
\hline & $\mathrm{N}_{1 \mathrm{~s}}$ & $\begin{array}{l}398.62 \\
400.03\end{array}$ & $\begin{array}{l}-\mathrm{N}=\mathrm{C}< \\
>\mathrm{C}-\mathrm{N}<\end{array}$ & $\begin{array}{l}23 \\
77\end{array}$ \\
\hline & $\mathrm{S}_{2 \mathrm{P}}$ & $\begin{array}{l}162.0,163.1 \\
163.4,165.2 \\
168.1,169.5\end{array}$ & $\begin{array}{l}-\mathrm{SS}_{-},-\mathrm{S}_{-} \\
>\mathrm{C}-\mathrm{S}- \\
>\mathrm{C}-\mathrm{SO}_{n}-\end{array}$ & $\begin{array}{r}40 \\
57 \\
3\end{array}$ \\
\hline
\end{tabular}

wires showed clear peaks for $\mathrm{C}_{1 \mathrm{~S}}, \mathrm{~N}_{1 \mathrm{~S}}$, and $\mathrm{S}_{2 \mathrm{P}}$. In the former, peaks for $\mathrm{Fe}_{2 \mathrm{P}}$ and $\mathrm{Fe}_{3 \mathrm{P}}$ were observed. In the latter, none could be detected, indicating the latter to be thus more homogeneous. Assignments of peaks in the $\mathrm{C}_{1 \mathrm{~s}}, \mathrm{~N}_{1 \mathrm{~s}}$, and $S_{2 P}$ narrow spectra of DB-treated wires showed the formation of the DB disulfide polymer. Assignments of peaks in the $\mathrm{C}_{1 \mathrm{~S}}, \mathrm{~N}_{1 \mathrm{~S}}$, and $S_{2 P}$ narrow spectra of DB and TAIC treated wires indicated the formation of a three-dimensional polymer containing monosulfide and disulfide groups. The monosulfide group is formed by the addition of $\mathrm{C}=\mathrm{C}$ bonds to TAIC and -NHCS- groups in DB. ${ }^{15}$ The disulfide group is formed by oxidative reactions between NHCS groups in DB in air.

\section{Mechanism for Tribological Polymerization}

The activity of mechanically deformed metal may be due either to (1) high temperature and pressure at the point of working contact, ${ }^{16}$ (2) newly formed nascent surfaces, ${ }^{17}$ (3) lattice disorders, ${ }^{18}$ or (4) exoelectrons. ${ }^{3}$ The polymerization of DB on iron requires the presence of oxygen and high temperature. ${ }^{15}$ Surface temperatures of steel wires during drawing have been examined by Middiemiss. ${ }^{9}$ For an areal reduction of $9.8 \%$ and drawing rate of $50 \mathrm{~m} \mathrm{~min}^{-1}$, surface temperature reaches about $120-140^{\circ} \mathrm{C} .^{19,20}$ At $80^{\circ} \mathrm{C}$, DB cast film was not polymerized at all on an ordinary iron plate but at $120^{\circ} \mathrm{C}$ in air, DB film gave a polymer film on the plate and its melting point was $140^{\circ} \mathrm{C}$. DB was polymerized in the solid state. At $120^{\circ} \mathrm{C}$ in nitrogen atmosphere, DB film was hardly polymerized on the ordinary iron plate. Active iron and inactive plates were prepared for clarification of the effects of surface activity toward DB. The active plate was initially polished with $8 \mu \mathrm{m}$ grain emery and degreased for $3 \mathrm{~min}$ at $20^{\circ} \mathrm{C}$ ultrasonically under methanol. The inactive plate was prepared by heating the active iron plates for 24 hours at $150^{\circ} \mathrm{C}$ in air oven. The surface activity of the iron 
plate was a major determining factor of the polymerization activity of DB in air. The inactive and ordinary iron plates gave low polymerization activity to $\mathrm{DB}$. The active iron plate imparted high polymerization activity to DB under the same conditions. The contribution of a nascent surface or exoelectrons to the polymerization of DB may be the reason for these differences. That is, polymerization may be strongly influenced by surface activity.

It thus follows that the polymerization of DB on steel wires during drawing requires oxygen, heat, and a nascent surface or exoelectrons. Thiol compounds are oxidized by oxygen in air in the presence of $\mathrm{Fe}^{+2}$ to give disulfides. ${ }^{17,18}$ Ferrous cations may be formed on a nascent iron surface during drawing. DB produces dithiyl radicals in the presence of ferrous cations and oxygen as shown in eq 1 (Fig. 1). Dithiyl radicals react with each other to give disulfide polymers as shown in eq 2 . Dithiyl radicals of DB make addition to double bonds in TAIC to give three-dimensional monosulfide polymers and at the same time, coupling reactions which produce disulfide polymers, as shown in eq 3 . The addition of DB to TAIC on glass and inactive iron plates left for a long time in air failed to occur for $60 \mathrm{~min}$ at $120^{\circ} \mathrm{C}$. This would imply the formation of dithiyl radicals on a nascent surface during drawing.

In conclusion, by tribological polymerization, it should be possible to unifying metal processing and surface treatment. This in turn should lead to ultimate surface treatment of metals because it can be carried out easily in a very short time at low cost.

\section{REFERENCES}

1. A. B. Taubmann, L. P. Yanova, and G. S. Blyskosh, J. Polymer Sci., A-1, 9, 27 (1971).

2. Y. Momose, K. Yamada, and K. Nakagawa, $J$. Polymer Sci., Polym. Lett. Ed., 12, 623 (1974).

3. Y. Tamai and S. Mori, Z. Anorg. Allg. Chem., 476, 221 (1981).

4. S. Mori, O. Kuriyama, and Y. Tamai: Z. Anorg. Allg. Chem., 492, 492 (1982).

5. Y. Tamai, Junkatsu, 28, 231 (1983).

6. Y. Tamai, Junkatsu, 30, 76 (1985).

7. L. Grunberg, Proc. Phys. Soc., 66B, 153 (1953).

8. K. Mori, S. Sai, A. Watanabe, T. Miyashita, and M. Matsuda, Kobunshi Ronbunshu, 46, 819 (1989).

9. A. Middiemiss: Wire Industry, 34 (January 1972).

10. Y. Nakamura, T. Fujita, H. Kawakami, and Y, Yamada, Wire J., 59 (July 1976).

11. T. Cahill and K. Jones, Wire J., 47 (June 1978).

12. R. Phillips, M. J. Kelly, and M. Hurst, Wire J., 50 (March 1979).

13. N. A. Flanders and E. M. Alexander, Wire J., 60 (March 1979).

14. K. Mori and Y. Nakamura, Kobunshi Ronbunshu, 39, 93 (1982).

15. K. Mori, Y. Oishi, T. Miyashita, and M. Matsuda, Polymer International, 28, 193 (1992).

16. P. A. Thiessen, "Grundlagen der Tribochemie," Akademie Verlage, Berlin, 1957.

17. L. E. ST. Pierre and R. S. Owens, Nature, 202, 1204 (1964).

18. R. Schrader, P. Nobst, G. Tetzer, and D. Petzold, $Z$. Anorg. Chem., 365, 255 (1969).

19. C. F. Collis, J. D. Hopton, and D. L. Trimm, J. Appl. Chem., 18, 330 (1968).

20. J. D. Hopton, C. J. Swan, and D. L. Trimm, $A d v$. Chem. Ser., 75, 216 (1968). 